\title{
Endogenous Opioids in the Etiology and Treatment of Multiple Sclerosis
}

\author{
IAN S. ZAGON • PATRICIA J. MCLAUGHLIN
}

Department of Neural \& Behavioral Sciences, H109, Penn State University College of Medicine, Hershey, PA, USA

Author for correspondence: Patricia J. McLaughlin, Department Neural \& Behavioral Sciences, H109, Penn State University College of Medicine, 500 University Drive, Hershey, PA 17033, USA. E-mail: pxm9@psu.edu Doi: http://dx.doi.org/10.15586/codon.multiplesclerosis.2017.ch8

\begin{abstract}
Endogenous opioids are enkephalins and endorphins that are primarily produced in the brain and have multiple actions throughout the body. Enkephalins and endorphins act at opioid receptors and their activity can be blocked by opioid antagonists. A small pentapeptide termed opioid growth factor (OGF), and chemically termed $\left[\mathrm{Met}^{5}\right]$-enkephalin, has been shown to have causative and therapeutic roles in experimental autoimmune encephalomyelitis (EAE), the animal model of multiple sclerosis (MS). Enkephalin levels are reduced in animals and humans during MS relapses, and may play a role in etiology. Exogenous therapy with OGF or endogenous stimulation of OGF by low dosages of naltrexone (LDN) reverse the course of progressive EAE and limit the number of relapses in relapsingremitting EAE. Individuals prescribed LDN report less fatigue and a better quality of life while using LDN. This chapter summarizes the information from studies using two different animal models of EAE, as well as two different treatment regimens of two different compounds-OGF or LDN. In all investigations, the presence of enkephalins resulted in beneficial effects.
\end{abstract}

Key words: $\beta$-endorphin; Endogenous opioids; Enkephalins; Receptor mediation; Relapsing-remitting EAE.

In: Multiple Sclerosis: Perspectives in Treatment and Pathogenesis. Ian S. Zagon and Patricia J. McLaughlin (Editors), Codon Publications, Brisbane, Australia. ISBN: 978-0-9944381-3-3; Doi: http://dx.doi.org/10.15586/codon.multiplesclerosis.2017

Copyright: The Authors.

Licence: This open access article is licenced under Creative Commons Attribution 4.0 International (CC BY-NC 4.0). https://creativecommons.org/licenses/by-nc/4.0/ 


\section{Introduction}

Endogenous opioids are a class of molecules that are produced in the brain and circulate widely throughout all organ systems. Endogenous opioids are neuropeptides and are derived from one of the two precursor genes-pre-proenkephalin A or pro-opiomelanocortin (POMC). These opioid peptides have a variety of neuralrelated functions and are often termed neuromodulators or neuro-immunomodulators. The designation "opioid" is based on their confirmed or presumed binding site of an opioid receptor within the brain tissue. However, this chapter details the role of enkephalins in multiple sclerosis (MS) that is neural-like but not necessarily associated with the brain or spinal cord function. As will be discussed, enkephalins also inhibit cell replication, and blockade of their interaction utilizing low dosages of the general opioid receptor antagonist naltrexone (i.e., low dosages of naltrexone [LDN]) reduce the symptoms of MS and improve the patient's quality of life. The discovery of endogenous opioid peptides in 1975 by Hughes and colleagues (1) followed the identification in 1973 of native opioid receptors in the brain and the gastrointestinal tract (2-4). The first endogenous opioids to be confirmed by radioactive ligand binding were $\left[\mathrm{Met}^{5}\right]$-enkephalin and [ $\left.\mathrm{Leu}^{5}\right]$ enkephalin $(5,6)$. These neuropeptides will be the focus in this chapter. $\left[\mathrm{Met}^{5}\right]$-enkephalin is also termed the opioid growth factor (OGF) to distinguish its role in cell replication (7).

\section{Endogenous Opioids-Source, Distribution}

Precursors for both enkephalins and endorphins are posttranslationally modified to yield single or multiple copies of the end product endogenous peptide. The primary location for synthesis and regulation is the brain, in particular the pituitary.

\section{STRUCTURE, SOURCE, AND DISTRIBUTION OF $\beta$-ENDORPHIN}

Endorphins are derived from a single prohormone termed POMC (8-10). The POMC gene consists of three exons and when processed yields two large fragments identified as adrenocorticotrophin hormone (ACTH, $16 \mathrm{kD}$ ) and $\beta$-lipotrophin hormone ( $\beta$-LPH). These proteins are further processed to yield the corticotrophin-like intermediate protein (CLIP), various forms of melanocytestimulating hormone $(\alpha-\mathrm{MSH}, \beta-\mathrm{MSH}$, and $\gamma-\mathrm{MSH})$, and $\beta$-endorphin. The $\mathrm{POMC}$ gene is conserved throughout evolution and is located on chromosome 2 p23.3 in humans. Although the first five amino acids of $\beta$-endorphin code for $\left[\mathrm{Met}^{5}\right]$-enkephalin, it is not considered a primary source for enkephalins. Most endorphins, of which there may be as many as 20 different derivatives, originate primarily in the pituitary and act as neurotransmitters, pain modulators, and anxiety suppressors. POMC is primarily expressed in the anterior and intermediate lobes of the pituitary, with each lobe being responsible for different peptide products (8). Corticotroph cells in the anterior pituitary secrete POMC peptides that control adrenal function, while melanotrophs of the 
pars intermedia secrete $\alpha$-MSH-associated peptides that influence hair and skin pigmentation. Nonneural tissues expressing POMC products include the adrenal, small intestines, reproductive tract, spleen, lung, liver, heart, and placenta. Given the diffuse presence throughout the body, POMC exerts a number of diverse functions $(9,10)$.

\section{STRUCTURE, SOURCE, AND DISTRIBUTION OF ENKEPHALINS}

The gene for several enkephalin peptides is pre-proenkephalin A (PPE) (11) from which six copies of [Met $\left.{ }^{5}\right]$-enkephalin and one copy of [Leu $\left.{ }^{5}\right]$-enkephalin, as well as a heptapeptide and octapeptide, are produced. The PPE gene is conserved, with prominent expression in the posterior pituitary, as well as axon terminals and cell bodies throughout the body. Comparable to POMC expression patterns, PPE has been detected in a variety of noncentral nervous system tissues including the adrenal medulla; the visual, gastrointestinal, and cardiovascular systems; and the placenta (12). Subcellular distribution of $\left[\mathrm{Met}^{5}\right]$ enkephalin in epithelium was determined by dual-labeled immunoelectron microscopy (13). OGF (i.e., [Met ${ }^{5}$-enkephalin) and its receptor were colocalized on the paranuclear cytoplasm and in the nuclei of keratinocytes in the stratum basale. Ultrastructural studies of immunolabeled material using 5 and $10 \mathrm{~nm}$ gold particles demonstrated that while OGF was not always bound to the OGF receptor (i.e., OGFr), it was frequently associated with the outer nuclear envelope (13).

\section{Mechanisms of Action and Receptor Mediation}

Enkephalins and endorphins are opioid receptor agonists (3, 4, 14, 15), and their activity is very much dependent on receptor mediation. Opioid receptors include the mu, delta, and kappa classical opioid receptors that have a seven-member transmembrane binding site on the cytoplasmic membrane. Another receptor, with little or no gene or protein homology to the classical opioid receptors, was identified and termed OGFr - this receptor is located on the outer nuclear membrane and mediates OGF's inhibitory action on growth (13).

\section{RECEPTOR MEDIATION-AGONIST ACTIVITY}

Opioid activity associated with $\beta$-endorphin is dependent on its C-terminal residues and loss of these amino acids substantially decreases the analgesic property of the peptide. $\beta$-endorphin shares many of the physiological actions of exogenous opiates such as morphine and has been documented in animal studies to have effects on analgesia, respiratory depression, vasopressin release, and cardiovascular homeostasis (8). $\beta$-endorphin levels have been shown to increase during pregnancy, with the most elevated levels reported during labor and delivery. Studies over the last few decades have suggested that endorphins can bind to any or all of the classical opioid receptors (mu, delta, and kappa), and some studies have suggested that there is a specific receptor for endorphin termed the epsilon (ع) receptor $(16,17)$. 


\section{RECEPTOR MEDIATION-ANTAGONIST ACTIVITY}

Receptor antagonists bind with different affinities to each opioid receptor disrupting the interaction between the enkephalin/endorphin agonist and the receptor $(16,17)$. Because the interactions can be reversible depending on the longevity of the antagonist-receptor complex, it is often the duration of the opioid receptor blockade that confers the action. Of importance to the therapeutic treatment of MS is the set of data showing that intermittent opioid receptor blockade based on LDN or single dosages of naloxone resulted in biphasic responses (18-20). Dichotomous biological responses following different dosages of naltrexone and thus different durations of opioid receptor blockade were first reported in 1983 (18). Low dosages $(0.1 \mathrm{mg} / \mathrm{kg})$ of naltrexone inhibited the growth of the neuroblastoma tumors, but higher dosages $(10 \mathrm{mg} / \mathrm{kg})$ of naltrexone were not more inhibitory and, in fact, resulted in enhanced tumor growth. This was the first indication that the action of receptor blockade did not directly correlate with antagonist dosage (18). These observations have been optimized to work in favor of therapeutic treatment of MS. Thus, LDN has become a widespread therapeutic used to safely inhibit inflammatory processes by inhibiting proliferation of T-lymphocytes and B-lymphocytes following a peripheral autoimmune trigger, and to inhibit T-cell infiltration into the CNS (17).

\section{Functions of Endogenous Opioids}

In general, $\beta$-endorphin binds to multiple opioid receptors and depending on the receptor, functions to diminish pain, equilibrates food metabolism, mediates cardiovascular regulation, as well as drives euphoric responses attributed to higher order emotional and neurological systems (9). It is suggested that since $\beta$-endorphin has few central nervous system-mediated effects when administered systemically because of the inherent difficulty for $\beta$-endorphin to cross the bloodbrain barrier, the effects of mediating analgesia and respiratory depression are not directly attributed to the peptide (9). Classical functions of enkephalins include neurotransmission and pain modulation $(1-6,21,22)$. Along with its role as a neurotransmitter, enkephalins alter calcium influx and cause direct hyperpolarization of neurons $(22,23)$. In regions of the spinal cord (e.g., substantia gelatinosa), pain perception is integrated by enkephalin-enriched fiber tracts. The periaqueductal gray region contains enkephalins that resolve analgesia and inhibit the release of excitatory neurotransmitters (6). High concentrations of enkephalins in the hypothalamus suggest a role for endocrine modulation. Other major enkephalin pathways are associated with motor activity, intestinal tract motility and peristalsis, limbic system regulation of emotional behavioral, and the hypothalamic neuroendocrine axis.

\section{ENKEPHALINS AS GROWTH FACTORS}

Although enkephalins were initially considered to function as neurotransmitters, in the early 1980s, it was demonstrated that one specific enkephalin-[Met ${ }^{5}$ enkephalin-regulated the growth of normal and abnormal cells and tissues, and 
hence was renamed opioid growth factor $(\mathrm{OGF})(7,12,24)$. OGF is a potent, reversible, species-unspecific, and tissue-nonspecific negative growth regulator with action that is opioid receptor mediated $(3,7,12,24)$. The peptide is autocrine and paracrine produced, secreted, and effective at concentrations consistent with physiological behavior. OGF is rapid in biologic action, quickly degraded, and obedient to intrinsic rhythms of the cell (e.g., circadian rhythm). With regard to the role of OGF in disease, OGF was successful at reducing tumor burden, limiting metastatic growth, and had few side effects (18). However, direct application of OGF is difficult to achieve outside of a clinical setting because OGF is rapidly metabolized and requires repeated infusions. Most cancer patients have normal or even elevated OGF serum levels but appear to lack sufficient numbers of intact OGFr.

Another group of diseases-autoimmune disorders-manifests with too little OGF. The hypothesis is that diminished levels of serum enkephalins are unable to control rampant proliferation of immune cells during a trigger event or flare. The etiology of MS remains a black box and most likely, there is no singular cause of MS. Endogenous opioids, or the lack thereof, may be a contributing factor, but the data are insufficient. At best, we are able to work with animal models, but unfortunately, animal models do not imitate MS precisely. The most consistent animal model establishes progressive MS, but most patients present with relapsing-remitting MS (RR-MS), and this form of MS has the least reliable animal model. Nonetheless, hypothesis-driven, controlled studies on the role of endogenous opioids and experimental autoimmune encephalomyelitis (EAE) have generated data, suggesting that enkephalins play an integral role in the disease process.

\section{Preclinical Studies of Enkephalins and EAE}

Two different animal models were established to study progressive EAE (25-29) and relapsing-remitting EAE (RR-EAE) (30-32). In the first model, C57Bl6/J black mice were immunized with myelin oligodendrocytic glycoprotein $\left(\mathrm{MOG}_{35-55}\right)$, whereas the SJL/J white mouse along with proteolipid protein $\left(\mathrm{PLP}_{131-165}\right)$ is required to establish the RR-EAE (25-32). Each animal model was established and subgroups treated with either OGF or LDN beginning either at the time of immunization (induction of disease) or after disease symptoms were visible for 2 days (established disease). In addition to clinical behavior, pathology, sensitivity, motor activity, as well as immune system responses were investigated.

\section{CHRONIC EAE WITH OGF TREATMENT BEGINNING AT THE TIME OF INDUCTION OF DISEASE}

Initial studies on the onset and progression of EAE examined OGF treatment beginning at the time of disease induction and reported that severity and disease indices were markedly reduced in OGF-treated mice relative to MOG-immunized mice receiving saline (25-27). Significant reductions in activated astrocytes and damaged neurons were observed in CNS tissue of animals treated with OGF; 
likewise, no lumbar spinal cord demyelination was detected in the mice receiving OGF or LDN. This was in sharp contrast to mice receiving a high dose of naltrexone which blocked receptors continuously from OGF activity, and again, supported the mechanism that duration of opioid receptor blockade is critical in defining the outcome. Thus, OGF and LDN had no deleterious long-term repercussions and did not exacerbate EAE but halted progression of disease, reversed neurological deficits, and prevented the onset of neurological dysfunction over a considerable period of time.

\section{CHRONIC EAE WITH OGF TREATMENT BEGINNING WITH ESTABLISHED DISEASE}

OGF given at the time of induction arrested the progression of disease; however, the effects of OGF on established disease are more clinically relevant $(28,29)$. Studies wherein mice were immunized and then treated with OGF or saline beginning 2 days after showing signs of clinical EAE disease were established. Within 6 days of OGF treatment, animals demonstrated significant reductions (45\% reduction) in their behavioral scores relative to mice receiving saline (Figure 1) (28). Behavior was attenuated for at least 40 days. Mice receiving OGF had only limp tails and wobbly gait in comparison with saline-treated EAE mice displaying paralysis of one or more limbs. OGF treatment initiated after the appearance of chronic disease also reduced the number of activated astrocytes and damaged neurons, and decreased demyelination and T-cell proliferation. More specifically, T-lymphocyte infiltration was evaluated by staining lumbar spinal cord sections with a CD3 antibody. After 20 days of drug treatment, CD3+ cell infiltration was reduced by $68 \%$ in EAE+OGF mice compared to the EAE+Vehicle group. Spinal cord demyelination was assessed by Luxol fast blue staining, and

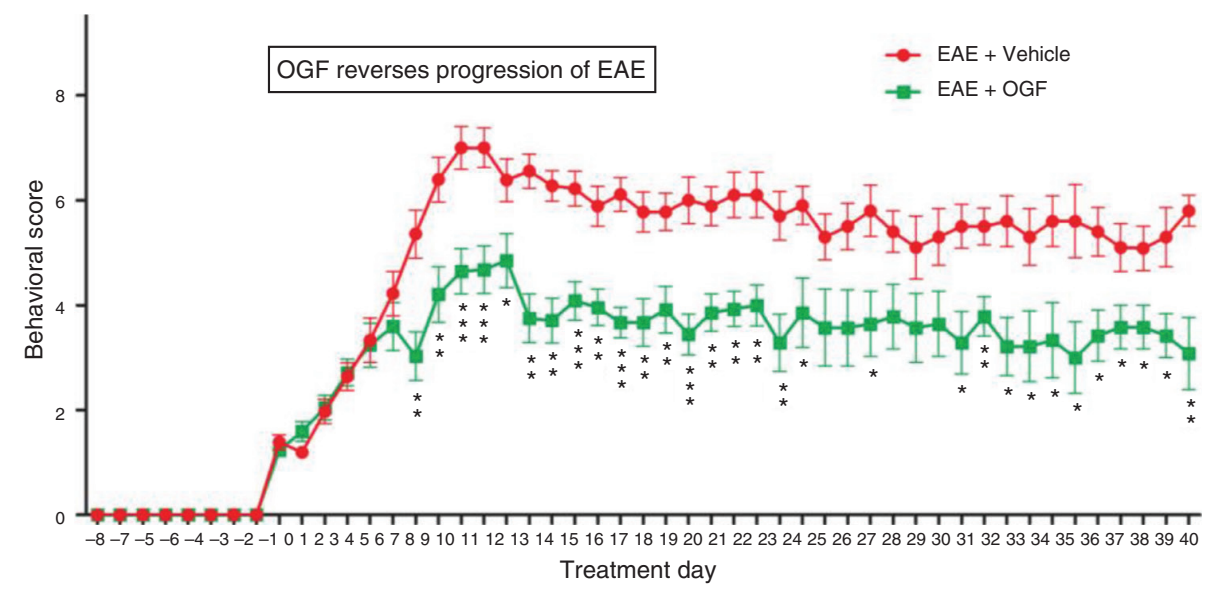

Figure 1 Clinical behavioral scores in $\mathrm{C} 57 \mathrm{BI} / 6 \mathrm{~J}$ mice immunized with $\mathrm{MOG}_{35-55}$ to induce chronic, progressive EAE and treated daily beginning at the time of established disease with either saline (EAE+Vehicle) or $10 \mathrm{mg} / \mathrm{kg}$ OGF (EAE+OGF). Values represent behavioral scores (scale of $0-10) \pm$ S.E.M. for at least 12 mice per group. Significantly different from saline controls at $p<0.05(*), p<0.01(* *)$, and $p<0.001\left({ }^{* *}\right)$. (Modified from Ref. (28).) 
after 20 days of EAE disease, EAE+Vehicle mice had approximately 13\% demyelinated white matter in spinal cord cross sections, compared to $8 \%$ or less in EAE+OGF animals. Neuronal damage as assessed by staining with SMI-32 antibody revealed that after 20 days of treatment, EAE+Vehicle mice had 4-fold elevations in SMI-32-positive neurons compared to normal controls, whereas EAE mice receiving daily OGF had only 2-fold elevations in SMI-32-positive neurons. In summary, the data from studies on exogenous therapy with enkephalins (i.e., OGF) and the progressive model of EAE support the use of OGF as a biotherapy for MS $(28,29)$.

\section{RR-EAE WITH OGF TREATMENT BEGINNING AT THE TIME OF INDUCTION}

Nearly $85 \%$ of the 2.5 million patients worldwide have RR-MS. Disease manifestation involves proliferation and activation of T-lymphocytes, microglia, and astrocytes, leading to inflammation, demyelination, and axonal damage. An animal model of RR-MS using proteolipid protein (PLP ${ }_{139-151}$ ) immunization of SJL mice was established to study RR-EAE (30-32). Within 9 days of immunization, behavioral signs of RR-EAE were observed. When OGF was administered at the time of disease induction, OGF-treated RR-EAE animals had less severe clinical disease than mice receiving saline and exhibited $66 \%$ reduction in median cumulative disease scores as well as prolonged periods of remission and diminished number and length of relapses (30). Neuropathological examination of lumbar spinal cord revealed reductions in the number of T-lymphocytes, microglia/macrophages, and activated astrocytes, with cell proliferation being targeted by OGF. Areas of myelination and neuronal damage were markedly reduced following OGF treatment during the 55-day observation period. OGF treatment led to the prevention of behavioral relapse for more than 36 days following the initial flare, with $85 \%$ of the mice returning to behavioral scores of 0 or 0.5 over the course of 5.5 weeks, and more than $70 \%$ of the mice showing remissions for more than 2 days. However, OGF administration at this dosage did not prevent the disease, nor did it "cure" the disease completely in any mouse.

\section{RR-EAE WITH OGF OR LDN TREATMENT BEGINNING AT THE TIME OF ESTABLISHED DISEASE}

Given the importance that OGF therapy was effective for relapsing EAE when the drug was given at the time of disease induction (30), a study was conducted on the effects of OGF treatment (31) or LDN (32) on established RR-EAE, with injections beginning 2 days after initial clinical signs of disease. Mice were immunized with subcutaneous injections of $100 \mathrm{mg}$ of myelin proteolipid protein $_{139-151}$. Clinical disease appeared with 9 days of immunization, and either OGF or LDN treatment was initiated. OGF reduced clinical behavioral scores and increased the number and duration of remissions (Figure 2). Over the course of 40 days of treatment, $42 \%$ of mice in the RR-EAE+OGF group had at least one remission compared to only 1 of 13 mice in the RR-EAE+saline group. Five OGF-treated mice appeared to remain in a permanent remission. Spinal cord neuropathology was suppressed in OGF-treated mice. In particular, astrogliosis 


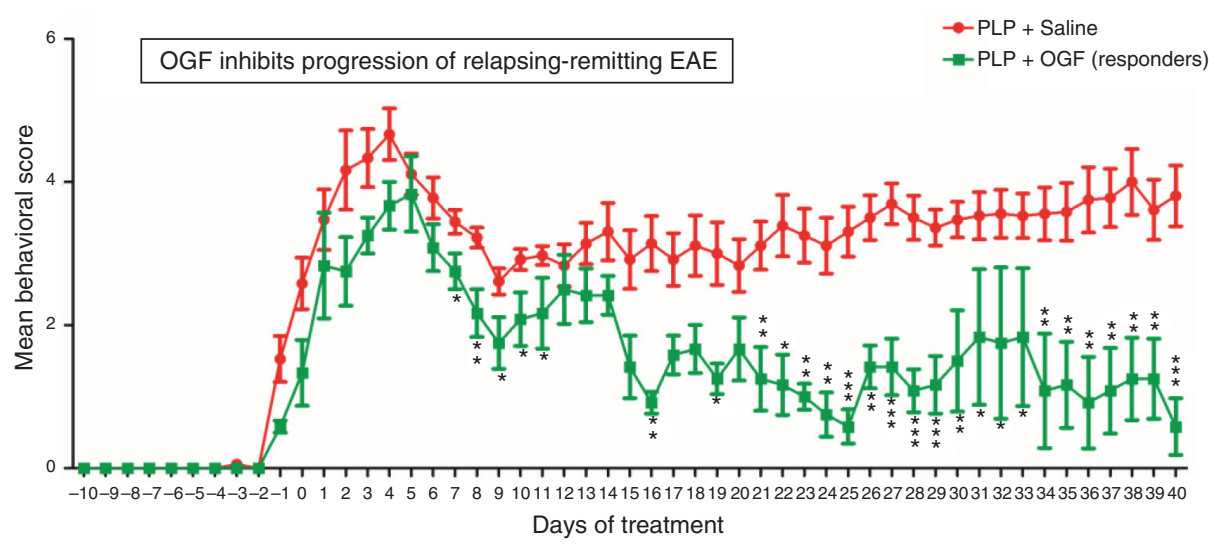

Figure 2 Clinical behavioral scores in SJL/J mice immunized with PLP $_{135-151}$ to induce relapsingremitting EAE and treated daily at the time of established disease with either saline (PLP+Saline) or $10 \mathrm{mg} / \mathrm{kg}$ OGF (PLP+OGF). Values represent behavioral scores (scale of $0-10) \pm$ S.E.M. for at least 12 mice per group. Significantly different from saline controls at $p<0.05\left(^{*}\right), p<0.01$ $(* *)$, and $\mathrm{p}<0.001\left({ }^{* * *}\right)$. Unpublished data.

was markedly reduced in comparison to saline-treated animals with RR-EAE. In a second series of investigations on RR-EAE, mice were immunized and, following the appearance of clinical disease, were injected with $0.1 \mathrm{mg} / \mathrm{kg}$ naltrexone (LDN) or saline daily for 40 days. Clinical behavior was markedly reduced in the RR-EAE mice receiving LDN relative to those mice on saline. Moreover, the length of complete remission was markedly elevated for mice receiving LDN, and the length of relapses was significantly decreased. These studies provide preclinical evidence that elevated enkephalins induced by either direct OGF injections or LDN therapy could provide positive changes in behavior and possibly extend periods of remission for individuals with MS.

\section{OGF REDUCTION OF T-LYMPHOCYTES AND B-LYMPHOCYTES}

The mechanism by which animal models for MS are derived involves the basic properties of immunization. Mice are inoculated with adjuvant containing myelin proteins and within days T-lymphocytes and B-lymphocytes are stimulated in peripheral tissues (e.g., spleen and lymph nodes) and begin to proliferate and then migrate to the central nervous system. Several studies were undertaken to examine the role of enkephalins, and the OGF-OGFr regulatory pathway, in T-cell and B-cell proliferation during each of these events (33-36). Initial studies investigated in vitro stimulation of T-cells and B-cells $(33,34)$. While this model falls short of mimicking clinical reality, the studies revealed that direct application of OGF or LDN to activated splenocytes inhibited T-cell and B-cell proliferation without requiring intervention from other immune system mediators.

Animal studies using both models of EAE confirmed our findings that OGF, exogenously or endogenously stimulated following LDN, inhibited T-cell and 
B-cell replication in vivo $(35,36)$. Examination of peripheral lymphocyte dynamics following immunization of mice with MOG antigen and treatment with OGF or LDN was conducted over a 2 -week period following immunization $(35,36)$. Isolated lymphocytes from spleens and draining inguinal lymph nodes were counted by flow cytometry, and the subpopulations of CD4+ and CD8+ T-cells, as well as B-lymphocytes, were noted. Within 5 days of treatment with exogenous OGF or LDN, the number of CD4+ and CD8+ T-lymphocytes in MOG-injected mice (no evidence of disease at this early time point) treated with OGF or LDN were reduced on average by 30\% from immunized, salinetreated mice. After 12 days of injections, mice receiving OGF or LDN had $32-37 \%$ reduction in the number of CD4+ T-cells, and 35-42\% reduction in CD8+ T-cells isolated from the spleen relative to cell number for saline-injected mice. As expected following immunization, B-cell number was elevated 2-fold in MOG-immunized mice relative to nonimmunized normal mice. OGF and LDN treatments markedly reduced the number of B220+ B-cells by approximately 29\% from the saline-injected MOG mice (35).

Additional investigations on the intracellular distribution of CNS-derived lymphocytes from lumbar spinal cord tissue were conducted on material collected on day 15 of OGF or LDN treatment. Cell homogenates were labeled with markers for CD4+ T-cells, as well as for cytokines that were expressed on Th1, Th2, and Th17 subsets of T-cells (35). OGF treatment resulted in approximately a 2-fold increase in the percentage of total lymphocytes that were CD4+ T-cells relative to the number recorded for saline-treated, MOG-immunized mice, as well as increasing the percentage of Thl-cell and Th17-cell subpopulations compared with saline-treated mice. LDN treatment did not alter the number of Th1, Th2, and Th17 subsets within 15 days (35), and no further studies have been pursued. In conclusion, exogenous enkephalins (i.e., OGF) or endogenous OGF following LDN suppressed T-lymphocyte and B-lymphocyte proliferation in the spleen and inguinal lymph nodes in the chronic progressive model of EAE specifically repressed replication of CD4+ and CD8+T-cells and B220+ B-lymphocytes in the spleen and lymph nodes of immunized mice within a week of immunization.

To examine the effects of enkephalins on the RR-EAE, autoreactive CD4 ${ }^{+}$ T-cells were followed as they migrated from peripheral tissues into the CNS (36). Immunohistochemical studies demonstrated that CNS-infiltrating CD3+ ${ }^{+} \mathrm{T}$-cells are diminished with exogenous OGF or LDN administration. Investigation of Th effector responses in CD4+ T-lymphocytes in the CNS suggested that modulation of the OGF-OGFr axis did not result in changes to Thl or Thl7 pro-inflammatory cytokines IFNY and IL-17, respectively, nor were there changes in the activity of anti-inflammatory Th2, IL-4 secreting cells. Overall, cell number was diminished, supporting the concept that enkephalins are immunomodulatory because of their anti-proliferative action.

\section{Clinical Studies}

Substantial progress has occurred in the treatment of MS over the last several years. At least 12 disease-modifying therapies (DMTs) have received FDA approval, and a few have been developed as oral medications (37-39). However, the financial 
burden of individual therapy can range upward to $\$ 60 \mathrm{~K}$ annually (37), and side effects still reduce compliance and thereby overall efficacy (38). Randomized clinical trials of enkephalins or LDN are limited (40-43), possibly because use of LDN has been reported to have a few side effects, and large pharmaceutical companies are not interested in sponsoring studies on a repurposed drug (i.e., LDN) that is already FDA approved at substantially higher dosages. Nonetheless, there remains a need for safe, effective treatments that are alternatives to the $\beta$-interferon products. With the widespread use of LDN (42-44) and the information available on many websites devoted to LDN, physicians are cautiously prescribing LDN.

Our findings in animal studies suggest that the endogenous opioid system is a worthwhile target for designing novel therapeutic interventions for MS. Two studies utilizing patient data from the Penn State Hershey Neurology Clinic revealed that individuals diagnosed with MS and offered LDN had no discernible side effects over extended periods of time $(45,46)$. A chart review performed through RedCap database focused on 215 MS patients who were provided a prescription for oral LDN (45). The study found that a significant number of patients benefit with LDN and an immodulating agent. Some patients preferred to take LDN as a monotherapy. The LDN did not cause any unexpected side effects. A second retrospective study was conducted at the Penn State Hershey Medical Center in patients who were diagnosed with RR-MS for up to a 9-year period (46). One group of patients $(n=23)$ were initially prescribed LDN the first time they visited the medical center. A second group of patients $(n=31)$ were treated with glatiramer acetate (Copaxone) and offered LDN as an adjunct therapy to their DMT. Patient visits after 1-50 months were evaluated in a retrospective manner. Data were obtained from patient charts that included laboratory values from standard blood tests, timed 25-feet walking trials, and changes in magnetic resonance imaging (MRI) reports. Statistical analyses between the groups and for each patient over time indicated no significant differences in clinical values, timed walking, or changes in MRIs following LDN alone. These data suggested that the inexpensive, nontoxic, biotherapeutic is safe and if taken alone did not exacerbate the disease symptoms.

Extension of this work has resulted in studies that have shown that animals with EAE $(47,48)$ or individuals with MS (48) have decreased enkephalin levels. Treatment with OGF or LDN restored serum enkephalin levels to normal and often correlated with reduced clinical behavior and restored sensitivity to pain and heat in mice. The animal work facilitated measurement of serum enkephalins in a longitudinal manner and was able to demonstrate that normal animals inoculated with $\mathrm{MOG}_{35-55}$ antigen expressed decreased enkephalins as the disease progressed $(47,48)$. This work is the first to suggest that OGF (chemically termed $\left[\mathrm{Met}^{5}\right]$-enkephalin) may be a specific marker for the onset of MS. Larger clinical trials measuring the serum enkephalins beginning at the time of first diagnoses, clinically isolated syndrome, are needed to confirm these observations. Nonetheless, the reports of aberrant enkephalin levels are not surprising given that exuberant proliferation of immune cells (e.g., T-cells and B-cells) are associated with MS, and that often administration of enkephalin to animal models was "immunosuppressant." While the end result was accurate (i.e., fewer T-cells and B-cells), the mechanism was not immunomodulatory, but rather inhibited cell replication related to the interaction of OGF and OGFr. 


\section{Conclusion}

The role of endogenous opioids in the cause and treatment of autoimmune diseases is at its infancy. Our focus on OGF and blockade of OGF action with naltrexone has provided a platform for preclinical studies of enkephalins and their role in MS. OGF is an inhibitory growth factor that downregulates replication of immune cells in response to antigens. OGF also inhibits gliosis that leads to the release of cytokines and inflammatory markers that facilitate demyelination and neurodegeneration. While there is no confirmatory data yet that low levels of enkephalins are suitable markers of other autoimmune diseases, there are a growing number of basic science and clinical reports that enkephalins, either exogenously administered or endogenously stimulated following receptor blockade with LDN, are effective treatments for progressive and RR-EAE and RR-MS.

Acknowledgment: This research was supported in part by generous funds from The Anna K. and Paul F. Shockey Family Foundation. The authors acknowledge the following graduate assistants who performed many of the preclinical investigations as the thesis component of their doctoral graduate studies: Dr. Kristen Rahn, Dr. Anna Kober, Dr. Leslie Hammer, and Dr. Michael Ludwig.

Conflict of interest: The authors declare no potential conflicts of interest with respect to research, authorship, and/or publication of this chapter.

Copyright and permission statement: To the best of our knowledge, the materials included in this chapter do not violate copyright laws. All original sources have been appropriately acknowledged and/or referenced. Where relevant, appropriate permissions have been obtained from the original copyright holder(s).

\section{References}

1. Hughes J, Smith TW, Kosterlitz HW, Fothergill LH, Morgan BA, Morris HR. Identification of two pentapeptides from the brain with potent opiate agonist activity. Nature. 1975;258:577-579. http:// dx.doi.org/10.1038/258577a0

2. Hughes J. Isolation of an endogenous compound from the brain with pharmacological properties similar to morphine. Brain Res. 1975;88:295-308. http://dx.doi.org/10.1016/0006-8993(75)90391-1

3. Pert CB, Snyder SH. Opiate receptor demonstration in nervous tissue. Science. 1973;179:1011-1014. http://dx.doi.org/10.1126/science.179.4077.1011

4. Simon EJ, Hiller JM, Edelman I. Stereospecific binding of the potent narcotic analgesic [3H]-etorphine to rat-brain homogenate. Proc Natl Acad Sci U S A. 1973;70:1947-1949. http://dx.doi.org/10.1073/ pnas.70.7.1947

5. Terenius L. Characteristics of the "receptor" for narcotic analgesics in synaptic plasma membrane from rat brain. Acta Pharmacol Toxicol. 1973;33:377-384. http://dx.doi.org/10.1111/j.1600-0773.1973. tb01539.x

6. Snyder SH. 2004. Opiate receptors and beyond: 30 years of neural signaling research. Neuropharmacology. 2004;7:274-285. http://dx.doi.org/10.1016/j.neuropharm.2004.06.006

7. Zagon IS, McLaughlin PJ. Identification of opioid peptides regulating proliferation of neurons and glia in the developing nervous system. Brain Res. 1991;542:318-323. http://dx.doi. org/10.1016/0006-8993(91)91585-O 
8. Raffin-Sanson ML, de Keyzer Y, Bertagna X. Pro-opiomelanocortin, a polypeptide precursor with multiple functions: From physiology to pathological conditions. Eur J Endocrinol. 2003;149:79-90. http://dx.doi.org/10.1530/eje.0.1490079

9. Tseng LF, Loh HH, Li CH. $\beta$-endorphin is a potent analgesic by intravenous injection. Nature. 1976;263:3239-3240. http://dx.doi.org/10.1038/263239a0

10. Van Loon GR, Appel NM. $\beta$-endorphin induced increases in plasma dopamine, norepinephrine, and epinephrine. Res Commun Chem Pathol Pharmacol. 1980;27:607-610.

11. Noda M, Furutani H, Takahashi M, Toyosato M, Notake S, Hakanishi S, et al. Isolation and structural organization of the human pre-proenkephalin gene. Nature. 1982;297:431-434. http://dx.doi. org/10.1038/297431a0

12. Zagon IS, Wu Y, McLaughlin PJ. Opioid growth factor and organ development in rat and human embryos. Brain Res. 1999;839:313-322. http://dx.doi.org/10.1016/S0006-8993(99)01753-9

13. Zagon IS, Ruth RB, McLaughlin PJ Nucleocytoplasmic distribution of opioid growth factor and its receptor in tongue epithelium Anat Rec. 2005;282A:24-37.

14. Simantov R, Snyder S. Morphine-like peptides in mammalian brain: Isolation, structure elucidation, and interactions with the opiate receptor. Proc Natl Acad Sci U S A. 1976;73:2515-2519. http:// dx.doi.org/10.1073/pnas.73.7.2515

15. Terenius L. Stereospecific interaction between narcotic analgesics and a synaptic plasma membrane fraction of rat cerebral cortex. Acta Pharmacol Toxicol. 1973;32:317-320. http://dx.doi. org/10.1111/j.1600-0773.1973.tb01477.x

16. Martin R. Opioid antagonists. Pharmacol Rev. 1967;19:462-521.

17. McLaughlin PJ, Zagon IS. Duration of opioid receptor blockade determines clinical response. Biochem Pharmacol. 2015;97:236-246. http://dx.doi.org/10.1016/j.bcp.2015.06.016

18. Zagon IS, McLaughlin PJ. Naltrexone modulates tumor response in mice with neuroblastoma. Science 1983;221:671-673. http://dx.doi.org/10.1126/science.6867737

19. Zagon IS, McLaughlin PJ. Duration of opiate receptor blockade determines tumorigenic response in mice with neuroblastoma: A role for endogenous opioid systems in cancer. Life Sci. 1984;35: 409-416. http://dx.doi.org/10.1016/0024-3205(84)90651-9

20. Zagon IS, McLaughlin PJ. Increased brain size and cellular content in infant rats treated with an opiate antagonist. Science. 1983;221:1179-1180. http://dx.doi.org/10.1126/science.6612331

21. Akil H, Watson SJ, Young E, Lewis ME, Katchaturian H, Walter JM. Endogenous opioids: Biology and function. Annu Rev Neurosci. 1984;7:223-255. http://dx.doi.org/10.1146/annurev.ne.07.030184.001255

22. Mudge AW, Leeman SE, Fischbach GD. Enkephalin inhibits release of substance P from sensory neurons in culture and decreases action potential duration. Proc Natl Acad Sci U S A. 1979;77:526-530. http://dx.doi.org/10.1073/pnas.76.1.526

23. Pert CB, Pasternak G, Snyder SH. Opiate agonists and antagonists discriminated by receptor binding in brain. Science. 1973;182:1359-1361. http://dx.doi.org/10.1126/science.182.4119.1359

24. Zagon IS, Verderame MF, McLaughlin PJ. The biology of the opioid growth factor receptor (OGFr). Brain Res Rev. 2002;38:351-376. http://dx.doi.org/10.1016/S0165-0173(01)00160-6

25. Zagon IS, Rahn KA, Turel AP, McLaughlin PJ. Endogenous opioids regulate expression of experimental autoimmune encephalomyelitis: A new paradigm for the treatment of multiple sclerosis. Exp Biol Med. 2009;234:1383-1392. http://dx.doi.org/10.3181/0906-RM-189

26. Zagon IS, Rahn KA, Bonneau RH, Turel AP, McLaughlin PJ. Opioid growth factor suppresses expression of experimental autoimmune encephalomyelitis. Brain Res. 2010;1310:154-161. http://dx.doi. org/10.1016/j.brainres.2009.11.026

27. Rahn KA, McLaughlin PJ, Zagon IS. Prevention and diminished expression of experimental autoimmune encephalomyelitis by low dose naltrexone (LDN) or opioid growth factor (OGF) for an extended period: Therapeutic implications for multiple sclerosis. Brain Res. 2011;1381:243-253. http://dx.doi.org/10.1016/j.brainres.2011.01.036

28. Campbell AM, Zagon IS, McLaughlin PJ. Opioid growth factor arrests the progression of clinical disease and spinal cord pathology in established experimental autoimmune encephalomyelitis. Brain Res. 2012;1472:138-148. http://dx.doi.org/10.1016/j.brainres.2012.07.006 
29. Campbell AM, Zagon IS, McLaughlin PJ. Astrocyte proliferation is regulated by the OGF-OGFr axis in vitro and in experimental autoimmune encephalomyelitis. Brain Res Bull. 2013;90:43-51. http:// dx.doi.org/10.1016/j.brainresbull.2012.09.001

30. Hammer LA, Zagon IS, McLaughlin PJ. Treatment of a relapse-remitting model of multiple sclerosis with opioid growth factor. Brain Res Bull. 2013;98:122-131. http://dx.doi.org/10.1016/j. brainresbull.2013.08.001

31. Hammer LA, Zagon IS, McLaughlin PJ. Improved clinical behavior of established relapsingremitting experimental autoimmune encephalomyelitis following treatment with endogenous opioids: Implications for the treatment of multiple sclerosis. Brain Res Bull. 2015;112:42-51. http:// dx.doi.org/10.1016/j.brainresbull.2015.01.009

32. Hammer LA, Zagon IS, McLaughlin PJ. 2015. Low dose naltrexone treatment of established relapsing-remitting experimental autoimmune encephalomyelitis. J Mult Scler (Foster City). 2015;2: 1000136.

33. Zagon IS, Donahue RN, Bonneau RH, McLaughlin PJ. B lymphocyte proliferation is suppressed by the opioid growth factor-opioid growth factor receptor axis: Implication of the treatment of autoimmune diseases. Immunobiology. 2011;216:173-183. http://dx.doi.org/10.1016/j.imbio.2010.06.001

34. Zagon IS, Donahue RN, Bonneau RH, McLaughlin PJ. T lymphocyte proliferation is suppressed by the opioid growth factor ([Met $\left.{ }^{5}\right]$-enkephalin)-opioid growth factor receptor axis: Implication for the treatment of autoimmune diseases. Immunobiology. 2011;216:579-590. http://dx.doi.org/10.1016/j. imbio.2010.09.014

35. McLaughlin PJ, McHugh DP, Magister MJ, Zagon IS. Endogenous opioid inhibition of proliferation of $\mathrm{T}$ and $\mathrm{B}$ cell subpopulations in response to immunization for experimental autoimmune encephalomyelitis. BMC Immunol. 2015;16:24. http://dx.doi.org/10.1186/s12865-015-0093-0

36. Hammer LA, Waldner H, Zagon IS, McLaughlin PJ. Opioid growth factor and low dose naltrexone impair CNS infiltration by CD4+ T lymphocytes in established experimental autoimmune encephalomyelitis. Exp Biol Med. 2016;241:71-78. http://dx.doi.org/10.1177/1535370215596384

37. Hartung DM, Bourdette DN, Ahmed SM, Whitham RH. The cost of multiple sclerosis drugs in the US and the pharmaceutical industry. Neurology. 2015;84:2185-2192. http://dx.doi.org/10.1212/ WNL.0000000000001608

38. Hadjigeorgiou GM, Doxani C, Miligkos M, Ziakas P, Bakalos G. A network met-analysis of randomized controlled trials for comparing the effectiveness and safety profile of treatments with marketing authorization for relapsing multiple sclerosis. J Clin Pharm Ther. 2013;38:433-439. http://dx.doi. org/10.1111/jcpt. 12090

39. Cree BA. Update on reproductive safety of current and emerging disease-modifying therapies for multiple sclerosis. Mult Scler. 2013;19:835-843. http://dx.doi.org/10.1177/1352458512471880

40. Cree BA, Kornyeyeva E, Goodin DS. Pilot trial of low-dose naltrexone and quality of life in multiple sclerosis Ann Neurol. 2010;68:145-150. http://dx.doi.org/10.1002/ana.22006

41. Sharafaddinzadeh N, Moghtaderi A, Kashipazha D, Magdinasab N, Shalbafan B. The effect of lowdose naltrexone on quality of life of patients with multiple sclerosis: A randomized placebo-controlled trial. Mult Scler. 2010;16:964-969. http://dx.doi.org/10.1177/1352458510366857

42. Raknes G, Smabrekke L. A sudden and unprecedented increase in low dose naltrexone (LDN) prescribing in Norway. Patient and prescriber characteristics, and dispense patterns. A drug utilization cohort study. Pharmacoepidemiology Drug Safety. 2017;26:136-142. http://dx.doi.org/10.1002/ pds. 4110

43. Younger J, Parkitany L, McLain D. The use of low-dose naltrexone (LDN) as a novel antiinflammatory treatment for chronic pain. Clin Rheumatol. 2014;33:451-459. http://dx.doi. org/10.1007/s10067-014-2517-2

44. Parkitny L, Younger J. Reduced pro-inflammatory cytokines after 8 weeks of low-dose-naltrexone for fibromyalgia. Biomedicines. 2017;5:16.

45. Turel AP, Oh KH, Zagon IS, McLaughlin PJ. Low dose naltrexone (LDN) for treatment of multiple sclerosis: A retrospective chart review of safety and tolerability. J Clin Psychopharmacol. 2015;35: 609-611. http://dx.doi.org/10.1097/JCP.0000000000000373 


\section{Enkephalins and Multiple Sclerosis}

46. Ludwig MD, Turel AP, Zagon IS, McLaughlin PJ. Long-term treatment with low dose naltrexone maintains stable health in patients with multiple sclerosis. Mult Scler J Exp Transl Clin. 2016;92:1-11.

47. Ludwig MD, Zagon IS, McLaughlin PJ. Elevated serum enkephalins correlated with improved clinical outcomes in experimental autoimmune encephalomyelitis. Brain Research Bull. 2017;134:1-9. http:// dx.doi.org/10.1016/j.brainresbull.2017.06.015

48. Ludwig MD, Zagon IS, McLaughlin PJ. Serum $\left[\mathrm{Met}^{5}\right]$-enkephalin levels are reduced in multiple sclerosis and restored by low dose naltrexone. Exp Biol Med. 2017;2:2055217316672242. http://dx.doi. org/10.1177/1535370217724791 